\title{
A Proposal for Supply-chain Improvements in a Luxury Company
}

\author{
Nathalia Tupinambá Karmaluk Tinoco*, Ricardo Augusto Cassel*, \\ Juliano Denicol* \\ * Federal University of Rio Grande do Sul (UFRGS), Industrial Engineering Department, Porto \\ Alegre, Brazil.
}

\begin{abstract}
The fashion market is becoming more competitive in the luxury industry, mainly because of the appearance and strengthening of other industries that provide new products more consistently to its customers. This sector, marked by its two annual collections and its unique items, must become more flexible and provide a faster response to its consumer base. In this context, supply chain management is an important factor in determining the degree of competitiveness of a company. This paper proposes tools to assist in the production scheduling of a luxury industry through making its supply chain more flexible by reducing the number of items delivered before the release, thus allowing the company to react according to the sales. To achieve that, an approach to the calculation of orders based on sales forecasts and on the lead time between stores and distribution centers was developed, in addition to a tool to control the delivery of the items through better integration with the suppliers. The proposed approach reduced the number of items in the first two orders by $17 \%$ and $12 \%$, and several delays were avoided through the utilization of the order-control tool.
\end{abstract}

Keywords: Supply chain management (SCM); Integration with suppliers; Distribution requirements planning (DRP); Fashion accessories; Luxury company.

\section{Introduction}

Trends in the fashion market have changed in recent years. The luxury business sector, which before relied on customer's loyalty to their products, saw these same clients be seduced by the fast-fashion sector. The capacity to be able to constantly offer new products to the market, such as is the case of the Spanish brand Zara, increased competitiveness in the fashion market, forcing luxury companies to seek ways to adapt to this change (Reinach 2005).

Luxury firms are characterized by the importance given to the brand name and its exclusivity as a way of attracting customers. Fast fashion, on the other hand, is characterized by quick responses to the consumer and to the changes in fashion trends. Although these two branches of the fashion market have almost opposite characteristics, luxury companies have been changing in order to become more agile, like the fast-fashion companies. Among changes can be mentioned the release 
of a pre-collection with some exclusive pieces, which is an addition to the two annual collections (Reinach 2005).

In this context, an essential topic is supply chain management, which, in the current competitive world, has become one of the most important factors in determining the degree of competitiveness of a company (Slack et al. 2007). It is vital to understand that, in order to have an efficient supply chain, it is not enough to have the latest technology and optimized processes, but that it also requires skilled and communicative professionals. Giunipero et al. (2006) stated that these professionals should focus not only on reducing costs, but also on their company's integration and collaboration with suppliers.

The objective of this study is to offer tools to aid in the supply process of a fashion-sector company in order to make its supply chain more flexible. When dealing with suppliers, one of the key points is the order placement by the buyer (Giunipero et al. 2006). This paper presents a case study of a company where the calculation of the orders sent to suppliers was modified to include the lead time between the different storage centers in order to achieve a more approximate calculation of the required quantities of products. Thus, current flexibility is expected to increase, which will allow the company to react according to the sales, ordering more or less of each product according to the observed demand.

Another point to be considered is that, by including the lead time between storage centers, the safety margin that existed before is lost. As a result, suppliers will not be able to permit delays to occur, because the calculation has become more accurate. Because the communication between the production team and suppliers becomes essential, with the development of informatics and telecommunication networks, there is a need for continuous control of information in order to process and transmit it quickly, and so to gain a competitive advantage and maintain a good level of efficiency.

\section{Literature review}

Slack et al. (2007) addressed the difficulty of separating production planning from control activities. Both try to conciliate the market demands and what operations can provide, however there are some characteristics that distinguish them. Planning, for instance, addresses what is expected to happen in the future without the guarantee that this event will happen, and therefore it is exposed to variations. The control, on the other hand, is used to make the necessary adjustments in order to mitigate the effects of these variations, based on indicators that detect what is happening in the system.

Due to the large competition between companies, supply chain management has become essential for an organizations' survival (Slack et al. 2007). According to Rollins et al. (2003), it is possible to create a general model of a supply chain that can be used as a basis for a more specific model for companies in the same sector. This reference model contains the elements that are common to the sector's operations. For the clothing and accessories sector, for instance, the authors stated that 
the chain begins with product design, going through production planning, manufacturing, and, ultimately, distribution of products to the stores.

Kim (2009) indicated that supply-chain integration plays a significant role regarding the supply chain management strategies, the capacity for competition, and the company's performance. In the early stages of the integration process, the level of integration has a direct role in the company's performance. However, as this process is implemented, it can be noticed that the level of integration has a direct role in the relationship between supply chain management and the capacity for competition, and an indirect one on the company's performance.

In that way, even if a company has great supply-chain-management practices and competitive ability, it is essential for its performance to have integration with suppliers. This is confirmed by Vickery et al. (2003), who added that information technology also has a direct role in the integration of the chain, which influences the customer service, and is ultimately linked to a company's performance.

Flynn et al. (2010) analyzed supply-chain integration through three dimensions: i) internal, between the sectors of the company; ii) with consumers; and iii) with suppliers, concluding that the internal integration forms a basis for integration with customers and suppliers. Thus, it is suggested that a company starts the integration process internally and afterwards moves on to the other two dimensions. Furthermore, Zhou et al. (2014) conclude that, to achieve good performance, it is necessary to have quality in the information exchanged among participants, which enables cost reduction for data collection and production control and increases the confidence level between the parties involved, a key factor for integration.

In the scope of the integration of a company with its suppliers, there are two flows, in opposite directions. The first is the flow of materials from suppliers to the company, considered as a "forward" integration. The second is the information flow from the company to suppliers, which is considered a "backward" integration. The importance of these two flows provides both opportunities and challenges for the companies, mainly due to the current trend to outsource activities that are not directly related to the core competence of the company. This trend emphasizes the need for greater integration, through the use of precise and current information (Prajogo and Olhager 2012).

Van der Vaart and Van Donk (2008) propose three categories through which it is possible to analyze supply chain management: practices, standards, and attitudes. Supply-chain practices can be defined as the activities or technologies that play an important role in the collaboration between the company and its suppliers or consumers. The standards of the interaction can be determined through the frequency in which information is exchanged. The attitudes, on the other hand, are related to the expectations about the relationship between the two parts. The authors conclude that, although the literature shows that there is a direct relationship between integration and company's performance, the study of these three categories enables better understanding of the relationship between suppliers and buyers. Prajogo and Olhager (2012) add that long-term relationships between companies and suppliers positively influence the exchange of information and communication between the 
two parties, as well as the company's performance. Also, the frequency, quantity, and quality of information are the main factors of this integration.

According to Bruce et al. (2004), for clothing and accessories companies, integration and good relationships with suppliers are the main factors to ensure their supply-chain flexibility. This is because these companies must be able to respond quickly to market changes, but cannot carry large inventory, because their products have a short life cycle, usually six months to a year.

\section{Methodology}

This study was carried out in five steps: i) data collection; ii) parameterization of the products information in order to use a Distribution Requirements planning (DRP) program; iii) creation of a tool to perform the orders' calculation using the new approach proposed; iv) comparison of the results obtained in both approaches; and v) creation of a tool to perform the orders delivery control.

\section{Results}

In this section, the results are presented after the application of the proposed methodology in this scheme: (i) the creation of different tools, using a new approach; and (ii) the validation of these tools, through comparison with previously used approaches.

\section{Data collection}

Data were collected regarding the products of the Fall-Winter 2013 collection, such as the registration code, release date, category, and supplier of each material, WDs safety stocks, which regions would receive a particular product, and the lead time between these regions and the WDs. These data were used to calculate the weekly demand at the stores, RWDs and CWD.

In addition, orders made for the collection were gathered, and were calculated with the former approach, where the different lead times between the stores and the WDs were not considered. Thus, many items were delivered ahead of time to regions nearby the CWD, or delayed for the most distant regions of the CWD.

\section{DRP program utilization}

The company's DRP program calculates how many parts must be ordered from the supplier per week, in order to not cause stock disruptions at the stores. This calculation is based on the sales forecast, on the amount of parts in stock at the CWD, and on lead times between the distribution centers. Although this tool cannot be used during the collection for seasonal products, since orders are made months before the release, it can be used to react according to the sales.

When there are no deliveries, and therefore, no stock at the CWD, the DRP calculation are based on the sales forecast and the minimum items necessary in every 
store, every week. Then, according to the lead time between the store and the RWD, this number of items needed is transferred-"x" weeks to RWD. Finally, the same happens between RWD and the CWD with the lead time of two weeks. In Fig. 1, for instance, the first lead time is equal to five weeks, and therefore, if they need to have 100 parts in the store in a given week, the items need to be at the RWD five weeks prior and at the CWD seven weeks prior.

A faulty point in this program is, however, that it has the correct amount of lead time only for the distribution between the CWD and the RWDs, considering it to be zero between RWDs and the stores. Thus, a tool was created in Excel that adjusts the calculation using the true value, in order to calculate the correct demand at the CWD. Since the company has been in business for a long time and controls the entire supply chain, lead times are known and suffer little or no variation, being two weeks between the CWD and the RWDs and ranging from one to eight weeks for the RWD to the stores.

In the tool developed, based on the product's information, Excel extracted information relating to the total quantity to be requested from the supplier, to the CWD and RWDs safety stocks, and to the lead time between WDs and the stores. Next, the weekly demand per store was copied from the DRP and linked with the right lead time, ending the existing gap and providing the correct calculation.

W-7 W-5 W

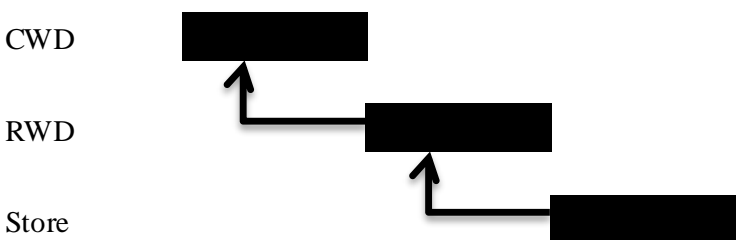

Fig 1 Lead time influence on demand between WDs and the stores

In addition, the DRP calculates that all the WDs safety stock must be delivered in a week, but the company's policy is to separate this amount in a period as long as four weeks, mainly to reduce losses from theft or damage to the shipments. Thus, the number of parts referring to the safety stock was copied from the program, representing the amount that should be at the WDs in each week. To that information, a certain percentage is applied by the company in order to distribute it over more weeks.

These two results, the correct demand in stores and the safety stock divided into shipments covering more than one week, were then copied to the DRP. Based on the sales forecast and lead times, the result was found for the quantity of pieces that should be at the distribution centers each week in order to avoid delays in deliveries to stores. 


\section{Orders Calculation}

Based on the real need for items at the CWD, it was possible to calculate the orders that were to be made to suppliers, which then established the delivery dates. These were determined in relation to the release date of each product, but usually five deliveries are made: i) six weeks before the release; ii) two weeks before; iii) two weeks later; iv) six weeks later; and v) eight weeks later. However, since it was observed that some managers vary the scheduled weeks, a tool that allows them to vary for each product was developed.

With the delivery dates defined, the orders were generated through the aggregation of the CWD weekly demands between deliveries. For example, if the first order must be delivered at week 30 and the second at week 34, the first must contain a sufficient amount of items so that the CWD does not have a disruption before the arrival of the second order, until the end week 33. All orders were calculated following this logic, except the last. As each product has a maximum number of items produced per collection, the last order was the difference between this amount and the sum of the other orders.

\section{Comparison between the Approaches}

To validate the new approach, the order calculation tool was applied to three different categories, two with external suppliers, categories " $\mathrm{X}$ " and "Z", and one whose products are produced at the company's own workshops, the category "Y ". Next, a comparison was performed between the obtained results and the data gathered in the first step of the methodology. It was possible to note that there was a reduction in the number of items of the first two orders and an increase in the last three, being higher in the last one. Fig. 2 shows the number of pieces per order of each approach.

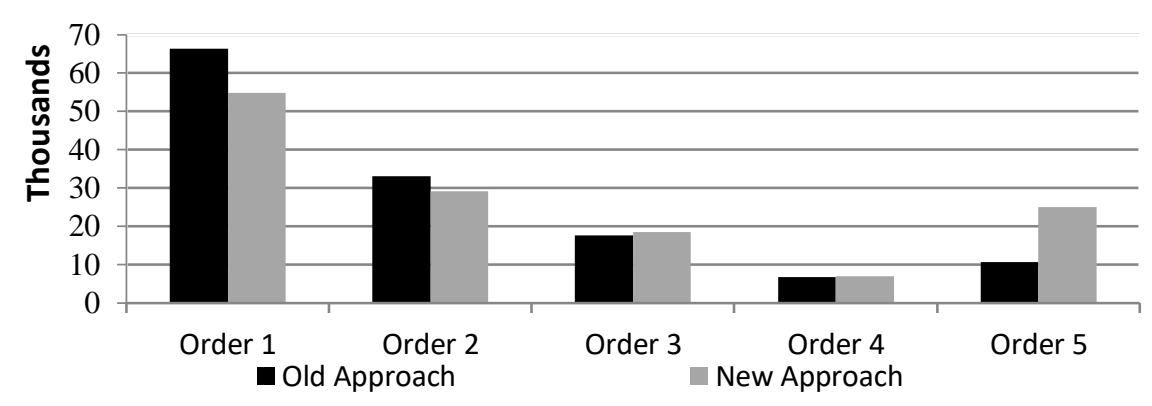

Fig. 2 Comparison between the old and the new approach

Tables 1 and 2 show, respectively, the comparisons per unit and the percentage between the two approaches, as well as the delivery reduction for each category. In general, there was an improvement with the tool use, since there was a decrease in the first orders. This was relevant because, prior to the first order receipt, twenty units should have undergone a quality test, and the order could not be delivered until these twenty pieces were approved. For instance, if three of the twenty were not 
accepted, then three pieces must be resent until a total of twenty have passed the test. This fact generates many delays, because it can take a while until they are all accepted and, if changes in manufacturing are necessary, all of the first order pieces that are ready up to that moment must go through rework. In addition, the increase in the number of items delivered after the launch was one of the program's goals, as it makes the supply chain more flexible, enabling changes to the amount based on the first weeks sales.

In Table 2, when the categories are separate, it is observed that the behavior of the category "Y" is not equal to the others. This difference is due to the fact that the relationship between the production team, responsible for making the orders, and the industrial team, representatives of the suppliers, is different between such categories. For the "X" and "Z", since they are external to the company, orders were made monthly and rarely changed. In the "Y" category, as the industrial team is the provider, the orders, even in the old approach, were reviewed weekly and modified in accordance with the deliveries or sales, if the product had already been launched, which enabled a smaller amount to be requested at the beginning, since it could be modified later.

Table 1 Comparison between the two approaches

\begin{tabular}{lcccccc}
\hline $\begin{array}{l}\text { Ap- } \\
\text { proach }\end{array}$ & $\mathbf{1}$ & $\mathbf{2}$ & $\mathbf{3}$ & $\mathbf{4}$ & $\mathbf{5}$ & Total \\
\hline Old & 66325 & 33166 & 17765 & 6796 & 10609 & 134661 \\
New & 54827 & 29213 & 18462 & 7056 & 25103 & 134661 \\
\hline & $-17 \%$ & $-12 \%$ & $4 \%$ & $4 \%$ & $137 \%$ & \\
\hline
\end{tabular}

Table 2 Reduction per category

\begin{tabular}{lcccccc}
\hline Category & Supplier & $\mathbf{1}$ & $\mathbf{2}$ & $\mathbf{3}$ & $\mathbf{4}$ & $\mathbf{5}$ \\
\hline $\mathrm{X}$ & Extern & $-49 \%$ & $-13 \%$ & $-39 \%$ & $-10 \%$ & $592 \%$ \\
$\mathrm{Y}$ & Intern & $12 \%$ & $12 \%$ & $-15 \%$ & $-35 \%$ & $-11 \%$ \\
$\mathrm{Z}$ & Extern & $-18 \%$ & $-19 \%$ & $66 \%$ & $108 \%$ & $539 \%$ \\
\hline General & & $-17 \%$ & $-12 \%$ & $4 \%$ & $4 \%$ & $137 \%$ \\
\hline
\end{tabular}

Similarly, it was noticeable that certain products, within the categories " $\mathrm{X}$ " and "Z", experienced an increased in items in the first order. Since they are exact cases, it was concluded that, with the previous approach, a demand lower than the real one was calculated.

\section{Orders Delivery Control}

After the orders are calculated and passed on to suppliers, the control of the deliveries is fundamental by comparing them both with the pre-established date and with the demand. For such, a tool to gather this information was created, which must be updated by the production and by the industrial teams. It aims to achieve the integration between the two teams, and should be easy to use and contain important and 
updated data. It was possible to observe that, despite the orders being placed with fixed delivery dates, the suppliers, most of the time, performed weekly deliveries rather than monthly ones. This weekly planning was also added to the tool, with the industrial team being responsible for updating it. In this way, it was possible to compare the real deliveries and the demand weekly, and the cumulative deliveries and the requested orders monthly.

Fig. 3 shows the overall situation concerning the collection the accumulated data. The gray and black vertical lines represent, respectively, the week in which the file is being updated and the release date. The dashed gray line shows the orders that were requested. The thick black line shows the parts that have already been delivered, and the dashed black line shows the vendor's planning for future deliveries. The area in dark gray indicates the demand, and the area in light gray, the safety zone. The latter is equal to the dark gray, shifted two weeks, and its purpose is to draw the attention of the production and industrial teams for when the black or gray lines, of orders and deliveries, enter this area.

After being developed, the tool was tested with three industrial staff members as a pilot, with the purpose of finding points for improvements. There was no training, and all explanations were conducted via video conferencing, which proved the easiest to use. An example of the tool use can be seen in Fig. 3. It is easy to see that the order of the second week of 2014 (S201402) could not have delays because it would result in a delay in the items' delivery to the stores, since there is no margin between the order quantity and the demand. Observing this, the supplier changed its planning to advance the delivery of this order, providing a higher margin.

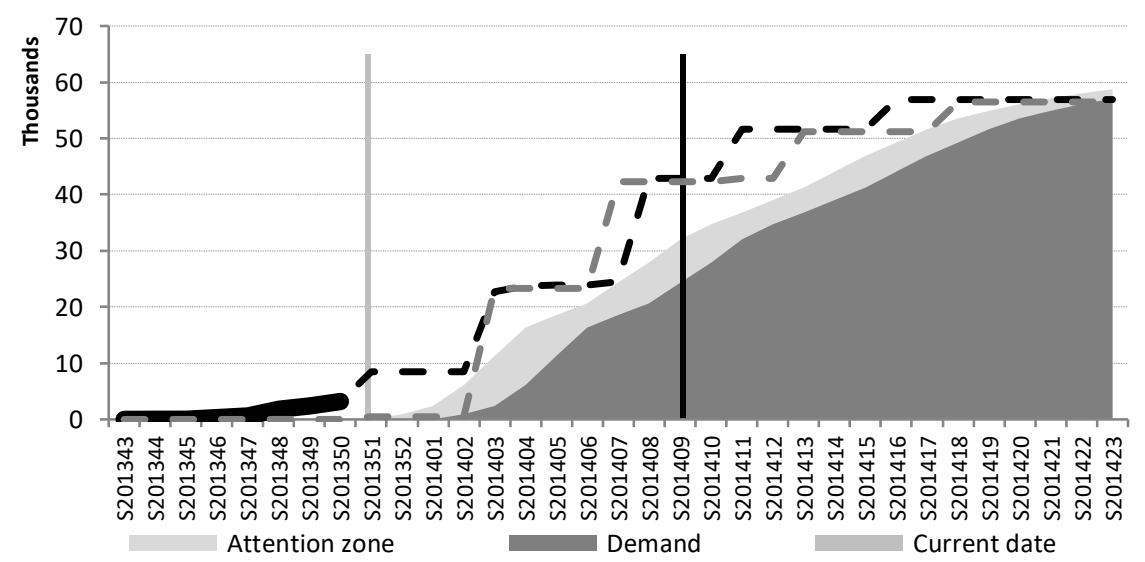

Fig. 3 Collection situation

One of the improvements requested by members, who have utilized the tool, is the service-level calculation, which is one of the indicators most commonly used by the company. The required data were already on the chart, since it is given by the relationship between full black lines and the gray dashed line, i.e., deliveries performed and orders. Therefore, a field highlighting this information was added. 
Moreover, as this tool is updated weekly, suppliers may change the deliveries planning and improve this percentage from one week to another.

Another type of information added after the tests were performed was the items backlog. With the schedule of deliveries information from suppliers and the quantity of parts delivered, it was possible to calculate how many items were missing and how many extra items were delivered. With that, suppliers can increase or decrease the number of items to be delivered in the following week in order to not damage the service level.

Since the tests with the three members of the production team occurred without major problems and they quickly adapted to the tool and to its routine of weekly updates, the tool stepped out of the pilot mode and was applied to all categories. A meeting with all members of the two teams was organized where all the points were explained, from the change in the orders calculation up to the pilot project conduction, emphasizing that collaboration between the two teams was essential.

The implementation to all products occurred rapidly, and everyone adapted to the routine of the tool, perceiving its importance. By talking to team members, it was observed that they understood the objective of maintaining better control of supplier deliveries, and that the tool optimized this control and avoided many delays that would probably not have been avoided with the previously used tools. The old tools were updated less frequently, and, therefore, it sometimes took too long to notice a delay, with the situations already being irreversible by the time they were discovered.

\section{Conclusion}

Due to the changes that have been occurring in the fashion market, with the increase of competition and the emergence of new items on the market, it became necessary for luxury companies to adapt and become more flexible. The objective of this study was to propose tools to assist the luxury companies in this change, focusing on supply chain and production scheduling. To this end, the calculation of the quantity of parts required per week was refined with the addition of lead time between the different RWDs and the CWD, being different from the old calculation, which assumed the same value for all RWDs.

One form of flexibility in the production chain is to enable a smaller number of products to be delivered before the release date, and the largest quantity delivered when there are already data concerning the sales. The methodology was applied in three categories of products, for suppliers with different characteristics. In the "X" and "Z" categories, which are external suppliers to the company, there was a reduction of $49 \%$ and $18 \%$, respectively, in the first order amount of items. In the "Y" category, which was an internal supplier, there was a $12 \%$ increase in this order. This is due to the fact that, in the latter, the number of items needed was reviewed weekly, and modified in accordance with the deliveries and sales, while in the first two, the orders were made months before delivery and were rarely changed. 
With a more refined calculation of the amount of items, there is less margin for error, and therefore better and stricter delivery control of orders is necessary. Thus, a tool was developed to take into account the number of parts required per week, the orders dates, amounts requested, and the delivered orders. The reaction obtained from the managers of the three categories was positive, and so the tool was easily implemented and became a part of their routine. In addition, it was observed that the tool promoted greater integration between the teams, avoiding possible delays which were identified early enough to be prevented.

Future developments include a comparison between the percentage of delay per collection, both before and after the implementation of the order control tool. Moreover, the estimation of cost reduction through lower inventories and reduced delays constitutes a topic of interest, as well as does the consideration of stochastic lead times between WDs.

\section{References}

Bruce, M., Daly, L., Towers, N. Lean or agile: A solution for supply chain management in the textiles and clothing industry? International Journal of Operations \& Production Management 24 (2), 151-170, (2004).

Flynn, B. B., Huo, B., Zhao X. The impact of supply chain integration on performance: A contingency and configuration approach. Journal of Operations Management 28 (1), 58-71, (2010).

Giunipero, L. C., Handfield, R. B., Eltantawy, R. Supply management's evolution: key skill sets for the supply manager of the future. International Journal of Operations \& Production Management 26 (7), 822-844, (2006).

Kim, A. W. An investigation on the direct and indirect effect of supply chain integration on firm performance. International Journal of Production Economics 119 (2), 328-346, (2009).

Prajogo; D.; Olhager, J. Supply chain integration and performance: The effects of long-term relationships, information technology and sharing, and logistics integration. International Journal of Production Economics 135 (1), 514-522, (2012).

Reinach, S. S. China and Italy: Fast fashion versus prêt a porter - towards a new culture of Fashion. Fashion Theory 9 (1), 43-56, (2005).

Rollins, R. P., Porter, K., Little, D. Modeling the changing apparel supply chain. International Journal of Clothing Science and Technology 15 (2), 140-156, (2003).

Slack, N., Chambers S., Johnston, R. Operations Management. Harlow: Prentice Hall, (2007).

Van Der Vaart, T., Van Donk. D. P. A critical review of survey-based research in supply chain integration. International Journal of Production Economics 111 (1), 42-55, (2008).

Vickery, S., Jayaram, J., Droge, C., Calantone, R. The effects of an integrative supply chain strategy on customer service and financial performance: an analysis of direct versus indirect relationships. Journal of Operations Management 21 (5), 523539, (2003). 
Zhou, H., Shou, Y., Zhai, X., Li, L., Wood, C., Wu, Z. Supply chain practice and information quality: A supply chain strategy study. International Journal of Production Economics 147, 624-633, (2014). 